\title{
DISSOLUÇÃO DE FRONTEIRAS: a obra performativa de Sophie Calle
}

\author{
DISSOLUTION OF BOUNDARIES: the performative work of Sophie Calle
}

\section{DISOLUCIÓN DE FRONTERAS: la obra performativa de Sophie Calle}

Sofia Rodrigues Boito ${ }^{1}$

\begin{abstract}
Resumo
O artigo analisa a obra Suite Vénitienne, da artista francesa Sophie Calle, utilizando instrumentos teóricos provenientes de diversos campos: as artes visuais, o urbanismo e a as artes cênicas. A autora pretende, a partir de tal estudo de caso, investigar como as obras contemporâneas promovem a dissolução das antigas categorias artísticas e das fronteiras que separam "arte" e "vida".
\end{abstract}

Palavras-chave: Fotografia, Performatividade, Situacionismo.

\begin{abstract}
This article analyses Suite Vénitienne, an artistic project from the french artist Sophie Calle, using theoretical tools from various fields: visual arts, urbanism and the scenic arts. The author intends, with the analysis of this specific work, to investigate how contemporary artistic works promote the dissolution of the old artistic categories and the boundaries that separate "art" from "life".

Keywords: Performativity, Photography, Situationism.

\section{Resumen}

El artículo analiza la obra Suíte Vénitienne, de la artista francesa Sophie Calle, utilizando herramientas teóricas de diversos campos: artes visuales, el urbanismo y las artes escénicas. La autora pretende, a partir de esta análisis, investigar cómo las obras contemporáneas favorecen la disolución de las viejas categorías artísticas y el límite entre "arte" y "vida".
\end{abstract}

Palabras clave: Fotografía, Performatividad, Situacionismo.

A fim de contribuir para a reflexão acerca das produções artísticas contemporâneas que diluem as fronteiras entre as linguagens e ocupam um território inclassificável, o presente artigo apresenta um estudo de caso feito pela autora na ocasião de sua dissertação de mestrado. A análise, focada na obra Suíte Vénitienne, da artista francesa Sophie Calle, pretende ser um ponto de partida para uma reflexão mais ampla sobre as obras contemporâneas que, com uma postura performática, desa- 
fiam a lógica da classificação em categoria estanques e instauram o que Eleonora Fabião intitula de Zonas de desconforto: "Como a performance indica, desafiar princípios classificatórios é um dos aspectos mais interessantes da arte contemporânea. A suspensão de categorias classificatórias permite o desenvolvimento de "Zonas de Desconforto" (FABIÃO, 2008, p. 239).

Calle figura entre as mais importantes e influentes artistas da atualidade e trabalha na intersecção entre diversas linguagens. Desafia críticos e estudiosos de arte, que já o classificaram tanto como autobiografia, como fotografia, instalação e/ ou performance. O presente artigo não pretende, no entanto, buscar uma categoria "correta" para a obra da artista, a fim de apaziguar o debate, mas fomentá-lo.

Charlotte Cotton (2010), em seu livro A fotografia como arte contemporânea, afirma que Calle é herdeira da arte conceitual, à medida que suas obras estão sempre pautadas em uma ideia, um recorte conceitual que se encontra por trás da imagem fotográfica. Assim como em Duchamp, seus trabalhos são materializações de enunciados, de gestos artísticos, muitas vezes mais importantes do que o resultado estético ou o objeto em si.

Duchamp caracteriza uma estrutura verbal com presença no espaço, estabelecendo, em relação ao objeto plástico, um procedimento discursivo disjuntivo, em que as conexões palavra/objeto são retraçadas a partir das marcas produzidas por cada uma das matérias sobre a outra. (BASBAUM, 2007, p.29)

No entanto, se para Duchamp as obras são materializações de gestos efetuados pelo artista, em Calle as obras são a concretização não apenas de um gesto, mas de um evento por ela criado e no qual ela envolveu seu próprio corpo, afetos e intelecto. Em Suíte Vénitienne (1980), por exemplo, a artista se propõe a seguir um desconhecido pelas ruas de Veneza: tratava-se de um homem que ela havia seguido por alguns minutos nas ruas de Paris e a quem ela foi apresentada, na mesma noite, em um vernissage. Na ocasião do vernissage, tal homem comenta com Calle que faria uma viagem à Veneza e a artista resolve, então, segui-lo durante sua estadia pela cidade. Ela, então, embarca sozinha em um trem, hospeda-se ao lado do hotel em que aquele homem estaria hospedado e inicia uma perseguição silenciosa ao desconhecido. Sua obra consiste em apresentar, posteriormente, um conjunto de fotografias e textos que ela produziu durante a execução de tal perseguição.

Assim, a artista se lança voluntariamente em uma situação real de "espionagem", experimentando suas reações físicas emocionais em um contexto de tensão e 
suspense. Ao assumir o papel de detetive, caçadora ou perseguidora voyeur, Calle cria um programa performático em que transforma o ato de "tirar uma foto" em uma ação performativa: ela sai literalmente à caça do homem que é seu objeto, seu tema e se lança nessa perseguição. A perseguição, aqui, como experiência, é o próprio substrato da obra. Sua busca não se encontra, portanto, pautada no futuro, nas imagens que ela obterá dessa caça, mas na vivência em tempo presente da ação por ela proposta. As lentes, assim, são mais do que suas cúmplices, são uma extensão de seus braços, é por meio delas que a artista age - transformando a simples ação de seguir alguém em uma ação de espionagem.

A câmera/arma não mata, portanto, a metáfora agourenta parece não passar de um blefe - como a fantasia masculina de ter uma arma, uma faca ou uma ferramenta entre as pernas. Ainda assim, existe algo de predatório no ato de tirar uma foto. Fotografar pessoas é violá-las, ao vê-las como elas nunca se veem, ao ter delas um conhecimento que elas nunca podem ter; transforma as pessoas em objetos que podem ser simbolicamente possuídos (SONTAG, 2004, p.15)

Em Suíte Vénitienne a artista assume, portanto, a busca e a crueldade voyeurística - características próprias da figura clássica do fotógrafo - como o norteador de sua ação performática. Baudrillard, em seu texto Please Follow Me, analisa da seguinte forma a obra:

Seguir o outro é controlar seu itinerário; é tomar conta da sua vida sem que ele saiba. É representar o papel mítico da sombra, que tradicionalmente segue você e protege você do sol - o homem sem sombra é exposto à violência da vida sem mediação - é para aliviar ele desse fardo existencial, a responsabilidade pela sua própria vida. Simultaneamente, ela, que segue, é ela própria liberada da responsabilidade pela sua própria vida, seguindo cegamente os passos de outro. [...] Seguindo-o, o outro, ela o substitui, troca de vida com ele, troca paixões, desejos, se transforma no outro. [...] Tudo está ali; a pessoa nunca deve entrar em contato, deve seguir, nunca deve amar, deve estar mais perto do outro que sua própria sombra. E deve desaparecer na paisagem antes que o outro olhe para trás. (BAUDRILLARD, 1983, p.82 tradução da autora) ${ }^{2}$

"Brincando" de ser a sombra desse homem desconhecido e apoderando-se de seu itinerário como se fosse o dela própria, Calle experimenta uma outra relação de alteridade. Tal qual um verdadeiro voyeur, a artista esquece-se de si, abandona suas próprias

2 "To follow the other is to take charge of his itinerary; it is to watch over his life without him knowing it. It is to play the mythical role of the shadow, wich, traditionally, follows you and protects you from the sun - the man without a shadow is exposed to the violence of a life without mediation - it is to relieve him of that existential burden, the responsibility for his own life. Simultaneously, she who follows is herself relieved of responsibility for her own life as she follows blindly in the footstep of the other. [...] Following the other, one replaces him, exchanges lives, passions, wills, transform oneself in the other's stead. [...] Everything is there; one must never come into contact, one must follow, one must never love, one must be closer to the other than his own shadow. And one must vanish into the background before the other turns around" 
opções de caminhos e atividades em Veneza, para se deixar levar por um estranho. Tal ação envolve a artista em um processo jogo em que ela assume por alguns dias o papel de detetive, como uma criança que cria uma brincadeira de "faz de conta" e a leva até as últimas consequências. Se utilizarmos aqui a perspectiva situacionista ${ }^{3}$, que considera o jogo como uma outra maneira de se relacionar com o mundo, ao criar novas alternativas para a própria vida, podemos afirmar que Calle se envolve em um processo lúdico para inventar novas possibilidades de relação com a realidade.

Os situacionistas querem criar novos jogos na vida cotidiana; o jogo situacionista é um jogo concreto, construído. Eles insistem na importância da invenção e criação de condições favoráveis para o desenvolvimento dessa paixão pelo jogo urbano, no valor do jogo, que seria o da própria vida livremente construída, sendo que a liberdade seria garantida pelas práticas lúdicas (JACQUES, 2012).

A liberdade alcançada por um jogador que cria suas próprias regras e, assim, inventa uma outra relação com a vida cotidiana, é o foco da obra de Sophie Calle. Nela, os espectadores são testemunhas da excitação, da tensão e das descobertas que a artista faz durante o desenvolvimento de sua atividade lúdica. A execução do jogo, aqui, gera imagens e textos imprevisíveis, que não estão submetidos a um julgamento clássico de obra de arte fotográfica ou literária, exatamente por serem parte de um processo e, portanto, não possuírem um caráter de objeto artístico "acabado", isto é, a de um resultado estético que vale por si só, independente do processo artístico que o gerou.

De fato, no cerne da noção de performance reside uma segunda consideração, a de que as obras performativas não são verdadeiras, nem falsas. Elas simplesmente sobrevêm. [...]. A esse respeito, os textos falam de "eventness". Ela coloca em cena, com esse fim, o processo. Ela amplifica, portanto, o aspecto lúdico dos eventos bem como o aspecto lúdico daqueles que dele participam (performers, objetos ou máquinas). (FÉRRAL, 2008, p.203)

A mulher que caminha pelas ruas de Veneza, perseguindo seu protagonista, não se distancia do evento em que está inserida, pelo contrário, está completamente submetida à duração do tempo presente - como uma criança durante o desenvolvimento de uma brincadeira. A cada respiração e a cada passo do homem que segue, sempre atenta para

30 situacionismo é um pensamento urbano criado por um grupo de artistas e pensadores franceses, reunido em torno de Guy Debord, que pretendia desenvolver ideias abordadas pelos surrealistas e, além disso, superar as questões artísticas para alcançar a esfera da vida cotidiana. A prática situacionista foi definida da seguinte maneira, segundo Paola Berenstein Jacques: "que se refere à teoria ou à atividade prática de uma construção de situações. Indivíduo que se dedica a construir situações; situação construída momento da vida, concreta e deliberadamente construído pela organização coletiva de uma ambiência unitária e de um jogo de acontecimentos". (JACQUES, 2012, p. 211) 
não ser percebida, ela desenvolve uma ação que só se configura no tempo mesmo de sua realização. No processo encarnado de vivência, a artista perambula pelas ruas de Veneza em um presente contínuo, já que, por se tratar de uma perseguição, ela percorre a cidade sem saber o que ocorrerá e ou o local para onde está sendo levada. Em uma relação literalmente labiríntica, como o Teseu que segue o fio de Ariadne, sua errância pela cidade italiana é diversa daquela de um turista ou de um fotógrafo tradicional. Ela se relaciona com a cidade sem um planejamento anterior, sem portar um mapa, nem ter objetivos claros, lançando-se em uma deriva ${ }^{4}$ e experimentando a cidade de uma maneira única.

Nessa experiência de deriva persecutória, a artista encarna a figura do detetive clássico. Aquele que segue o suspeito pelas ruas de uma cidade e camufla-se entre seus transeuntes. A figura de detetive que Calle encarna busca o anonimato em meio à cidade e à multidão. Mas, para que um espião passe incógnito uma condição é indispensável: a solidão. Dissolver-se nas ruas e entre os passantes, confundir-se no meio dos transeuntes, virar a esquina e atravessar a rua sem ser percebida, são atos solitários por excelência. A própria natureza da ação escolhida pela artista, exclui, portanto, a possibilidade de o espectador compartilhá-lo em tempo presente. E é aqui que a obra se diferencia da Performance art.

Sophie Calle precisa, então, encontrar formas de inserir o espectador em sua perseguição solitária e, para isso, apresenta sua obra como um diário aberto, com informações, fotografias e o relato dos principais passos que deu como "detetive".

19:00h - Um desconhecido passa por mim e me olha diversas vezes. Eu desvio o olhar, eu fixo, obstinadamente, o chão. O homem entra no restaurante 'La Colomba'.

$[\ldots]$

20:10h - O homem que tinha me olhado demoradamente sai do 'La Colomba'. Ele para diante de mim, se espanta em me encontrar no mesmo local, nesse frio. Ele quer saber se pode me ajudar em algo. Eu digo a ele que amo um homem - só o amor me parece desculpável - que está desde 18:15 no antiquário Luigi, em companhia de outra mulher. Eu peço a ele que entre e os encontre, para me contar o que ele vê. O homem consente. (CALLE, 2003, p. 92, tradução da autora $)^{5}$

4 "Entre os diversos procedimentos situacionistas, a deriva se apresenta como uma técnica de passagem rápida por ambiências variadas. O conceito de deriva está indissocialmente ligado ao reconhecimento de efeitos de natureza psicogeográficas e à afirmação de um comportamento lúdico-construtivo, o que o torna absolutamente oposto às tradicionais noções de viagem e de passeio" (DEBORD apud JACQUES, 2012, p. 213).

5 "19 heures. Un inconnu passe à plusieurs reprises devant moi. Je détourne les yeux, fixe obstinément le sol. L'homme entre au restaurant 'La Colomba'. 20h10. L'homme qui m'avait longuement regardée sort de 'La Colomba'. II s'arrête à nouveau devant moi, s'étonne de me trouver au même endroit, dans ce froid. II veut savoir s'il peut m'être de quelque secours. Je lui dis que j'aime un homme - seul l'amour me semble avouable - qui se trouve depuis $18 \mathrm{~h} 15$ chez l'antiquaire Luigi, en compagnie d'une autre femme. Je lui demande de les rejoindre et de me raconter à son retour ce qu'il aura vu. L'homme consent". 
Em Suite Vénitienne as imagens e os relatos textuais são, assim, expressão de uma experiência encarnada, subjetiva, na qual aquela que escreve e fotografa está sempre assumindo-se como sujeito inteiro, cujo corpo, mente e espírito são afetados pelo evento em que está inserido. Somos convidados, dessa forma, a adentrar a solidão e individualidade da performer. Isto é, se em uma obra de Performance art nos vemos envolvidos em um evento compartilhado em um mesmo tempo-espaço que $o$ artista, mas de um ponto de vista externo - isto é, do ponto de vista do espectador -, nessa obra estamos distanciados espaço-temporalmente do evento, porém, somos cúmplices das sensações que a performer teve no exato momento do desenvolvimento da ação. É como se pudéssemos experimentar do ponto-de-vista de uma câmera subjetiva - ou de um narrador em primeira pessoa - a experiência de Performance art.

As fotografias e os relatos são, assim, os instrumentos dos quais ela pode lançar mão para nos incluir em sua trajetória. Enquanto os textos nos oferecem a possibilidade de adentrar em sua mente e coração - expressando sua ideias e emoções -, as imagens fotográficas nos permitem ter acesso ao contexto exterior e à realidade do evento que a performer realizou. Tal qual um detetive que ostenta suas fotos como provas cabais de um crime, as fotos que a artista nos oferece são os vestígios de sua ação e a prova da existência concreta daquele homem. Assim como o espelho, a câmera fotográfica só pode retratar algo que esteve de fato materializado à sua frente, as fotos são as pegadas de luz de um objeto - que esteve diante da lente - na superfície do filme.

Podemos então, de certa forma, comparar as fotos de Suíte Vénitienne aos ready-mades de Marcel Duchamp, à medida que ambos são resultados intrínsecos de um gesto artístico. Isto é, a materialidade da obra é resultado direto da ação efetuada pelo artista - ação escolhida pelo seu desenvolvimento e não pelo seu resultado. $O$ objeto artístico, portanto, diz respeito apenas a esse gesto e nada mais. Ou seja, tal obra não precisa ser interpretada de maneira semiótica, pois em sua materialidade há a convergência de um ato executado. Se, no caso de Calle, a própria ação de fotografar é a experiência performática - ou o que torna a ação desenvolvida em experiência performática - as fotografias serão resultantes do engendramento dessa ação e não objetos simbólicos que dizem respeito a algo exterior a elas. Em Suíte Vénitienne as fotografias, mais do que quadros simbólicos a serem interpretados, são resultantes diretas de um processo. Para o projeto de Calle, portanto, o caráter indicial da fotografia - que a conecta física e concretamente com seu tema - é indispensável. É tal caráter (aqui potencializado) que permite que as imagens funcionem como provas, como 
pegadas, da ação proposta pela artista, contrapondo-se à concepção moderna da imagem fotográfica como sendo, puramente, uma superfície imagética.

[...] uma foto não é apenas uma imagem (como uma pintura é uma imagem),
uma interpretação do real; é também um vestígio, algo diretamente decalcado
do real, como uma pegada ou uma máscara mortuária. Enquanto uma pintura,
mesmo quando se equipara aos padrões fotográficos de semelhança, nunca
é mais do que a manifestação de uma interpretação, uma foto nunca é menos
do que o registro de uma emanação (ondas de luz refletidas pelos objetos) -
um vestígio material de seu tema. (SONTAG, 2004, p. 170)

No entanto - e aqui reside a tensão nas obras de fotografia performada - mesmo quando a fotografia tem seu caráter indicial potencializado, ela ainda pertence ao campo das imagens e, como tal, possuem um "caráter mágico". Isto é, sua natureza instaura a suspensão do fluxo temporal, sendo capaz de descolar uma cena do evento em que, um dia, ela esteve inserida.

A imagem fotográfica é uma fatia de tempo, um átimo de instante suspenso para toda a eternidade, em sua imobilidade, silêncio e descontinuidade. Uma forma de ver o mundo que só nos é fornecida única e exclusivamente pela fotografia. As fotografias de Calle, portanto, não dão conta de todo o processo de sua ação. E a escolha por essa linguagem não é casual. Tal aspecto misterioso, suspenso e mudo, próprio da imagem fotográfica, produz uma fricção como caráter processual e de atualização constante do programa performático. A opção que a artista faz pela fotografia, ainda que comprove a existência material daquele homem, daquela cidade, daquelas ruas e lugares, provoca a incerteza, cria frestas, lacunas de informação... Promove, então, a ambiguidade.

De fato, a figura presente nas fotos de Calle pode ser qualquer homem, pode ser um transeunte aleatório, assim como alguém que posou deliberadamente para a artista, fazendo-se passar por um homem desconhecido. A escolha da artista em nos apresentar fotos como prova da realização de sua ação, gera um grau de ambiguidade que levanta dúvidas sobre o que é real ou ficcional. Fotos são 'pseudo-presenças', como diria Susan Sontag, pois são pegadas de luz de algo que realmente esteve lá, mas não está mais. São pistas de algo. E é nesse ponto que Calle lança mão da fotografia, ela sabe que suas imagens não serão exatamente o objeto de sua perseguição, mas pistas dele, instantes de cenas que nos oferecem possibilidades de contato fugaz com sua experiência.

A fotografia nos coloca em contato com a realidade, mas de modo incompleto: atesta a presença do objeto, mas pouco diz sobre ele. Trata-se de um apontamento vigoroso, porém, quase mudo. Ao historiador cabe preencher algumas lacunas para formar um relato sobre essa realidade. Já os artistas percebem nesse 'silêncio' um espaço para o imaginário. (ENTLER, 2006, p.37) 
Não temos, assim, uma apreensão de trajetória completa da artista, como teríamos se ela tivesse escolhido a linguagem do vídeo - que se caracteriza por ser um fluxo contínuo de imagens. Temos acesso apenas a indícios, resquícios, sombras. $O$ tempo suspenso entre cada imagem fotográfica, a ausência de voz do homem perseguido - a única voz a que temos acesso é a da artista -, o filme em preto e branco, todos esses aspectos nos inserem em um universo de desconhecimento e mistério. $A$ artista consegue, assim, transmitir ao público a sua própria experiência de suspense e de mistério em relação a esse homem. Não temos certeza do que é real, do que é invenção, montagem, criação, experiência... Assim, as fotos criadas nesse tipo de trabalho são objetos em que a materialidade, de caráter indicial, se confunde com o campo simbólico gerado, isto é, a cena apresentada na imagem.

[...] a performance redefiniu duas relações de importância fundamental para a hermenêutica, assim como para a estética semiótica: primeiro, a relação entre sujeito e objeto, observador e observado, espectador e ator; em segundo lugar, a relação entre a materialidade e a semioticidade dos elementos da perfomance, entre significante e significado. (FISCHERLICHTE, 2008, p.26, tradução da autora) ${ }^{6}$

A artista vai além da atividade de uma fotógrafa que gera imagens recortadas do mundo. Com essa complexa arquitetura de programa performático, palavras e fotografias, a artista instaura uma experiência que coloca um debate mudo sobre os limites entre realidade e representação, vida-arte, subjetivo-objetivo. Seu gesto é performativo: "O performer instala a ambiguidade de significações, o deslocamento dos códigos, os deslizes de sentido. Trata-se, portanto, de desconstruir a realidade, os signos, os sentidos e a linguagem". (FÉRRAL, 2008, p. 203, grifo do autor)

A experiência de Calle, inserida na realidade, e não no campo da representação, transparece por trás de seu trabalho e gera a dissolução do caráter ficcional típico de obras artísticas. Sua produção não está no campo da ficção e do simbólico, já que a artista passou a atuar no próprio curso da vida, dos acontecimentos ditos "reais". Ademais, a inserção dessa experiência de jogo em um contexto artístico, a partir do enunciado implícito "isto é arte", confere ao seu trabalho um alto grau de ambiguidade - seriam elas narrativas ficcionais? Performances? Diários pessoais? Autobiografia? A partir do momento em que Calle efetua esse gesto, ela instaura um novo espaço-tempo que se encontra suspenso entre os acontecimentos da vida cotidiana e aqueles relativos à esfera artís-

6 "[...] the performance redefined two relationships of fundamental importance to hermeneutic as well as semiotic aesthetics: first, the relationship between subject and object, observer and observed, spectator and actor; second, the relationship between the materiality and the semioticity of the performance's elements, between signifier and signified." 
tica. Sua ação encontra-se em um território de fronteira, poroso, que extingue a dicotomia entre arte-vida, justamente por criar "uma situação em que o público foi suspenso entre as normas e regras da arte e as normas e regras da vida cotidiana, entre postulados da estética e postulados da ética". (FISCHER-LICHTE, 2008, p. 21, tradução da autora) ${ }^{7}$

\section{Bibliografia}

BASBAUM, R. R. Além da pureza visual. Porto Alegre: Zouk, 2007.

BAUDRILLARD, Jean. Suite Venitienne. Please Follow Me. Seattle: Bay Press, 1983.

CALLE, S. M'as-tu vue? Paris: Éditions du Centre Pompidou, 2003.

COTTON, C. A fotografia como arte contemporânea. São Paulo: Martins Fontes, 2010.

ENTLER, R. Testemunhos silenciosos: uma nova concepção de realismo na fotografia contemporânea. In: ARS, São Paulo, Departamento de Artes Plásticas da ECA/USP, n 8, 2006. Disponível em: <http://www.cap.eca.usp.br/ars8/entler.pdf>. Acesso em: 10 jul. 2012.

FABIÃO, Eleonora. Performance e teatro: poéticas e políticas da cena contemporânea. Sala Preta, Brasil, v. 8, p. 235-246, nov. 2008. Disponível em: <http://revistas.usp.br/salapreta/ article/view/57373>. Acesso em: 02 Jan. 2014. doi:http://dx.doi.org/10.11606/issn.22383867.v8i0p235-246.

FERÁL, Josette. Por uma poética da performatividade: o teatro performativo. Sala Preta, Brasil, v. 8, p. 197-210, nov. 2008. Disponível em: <http://revistas.usp.br/salapreta/article/ view/57370>. Acesso em: 02 Jan. 2014. doi:http://dx.doi.org/10.11606/issn.2238-3867. v8i0p197-210.

FISCHER-LICHTE, E. The transformative power of performance: a new aesthetics. Londres: Taylor\& Francis e-Library, 2008.

JACQUES, P.B. Elogio aos errantes. Salvador: EDUFBA, 2012.

SONTAG, S. Sobre fotografia. São Paulo: Companhia das Letras, 2004.

WHITECHAPEL GALLERY. Sophie Calle: talking to strangers. Londres: Whitechapel Gallery, 2009 [Curador da exposição: Andrea Tarsia].

Recebido em 28/02/2014

Aprovado em 17/04/2014

Publicado em 30/06/2014

7 " [...] created a situation wherein the audience was suspended between the norms and rules of art and everyday life, between aesthetic and ethical imperatives." 